\title{
A numerical study of aerosol influence on mixed-phase stratiform clouds through modulation of the liquid phase
}

\author{
G. de Boer ${ }^{1,2,3}$, T. Hashino ${ }^{4}$, G. J. Tripoli ${ }^{5}$, and E. W. Eloranta ${ }^{5}$ \\ ${ }^{1}$ The University of Colorado, Cooperative Institute for Research in Environmental Sciences, Boulder, CO, USA \\ ${ }^{2}$ NOAA Earth System Research Laboratory, Physical Sciences Division, Boulder, CO, USA \\ ${ }^{3}$ Lawrence Berkeley National Laboratory, Earth Sciences Division, Berkeley, CA, USA \\ ${ }^{4}$ University of Tokyo, Atmosphere and Ocean Research Institute, Chiba, Japan \\ ${ }^{5}$ The University of Wisconsin - Madison, Department of Atmospheric and Oceanic Sciences, Madison, WI, USA \\ Correspondence to: G. de Boer (gijs.deboer@ colorado.edu)
}

Received: 7 August 2012 - Published in Atmos. Chem. Phys. Discuss.: 28 August 2012

Revised: 1 February 2013 - Accepted: 4 February 2013 - Published: 15 February 2013

\begin{abstract}
Numerical simulations were carried out in a highresolution two-dimensional framework to increase our understanding of aerosol indirect effects in mixed-phase stratiform clouds. Aerosol characteristics explored include insoluble particle type, soluble mass fraction, influence of aerosolinduced freezing point depression and influence of aerosol number concentration. Simulations were analyzed with a focus on the processes related to liquid phase microphysics, and ice formation was limited to droplet freezing. Of the aerosol properties investigated, aerosol insoluble mass type and its associated freezing efficiency was found to be most relevant to cloud lifetime. Secondary effects from aerosol soluble mass fraction and number concentration also alter cloud characteristics and lifetime. These alterations occur via various mechanisms, including changes to the amount of nucleated ice, influence on liquid phase precipitation and ice riming rates, and changes to liquid droplet nucleation and growth rates. Alteration of the aerosol properties in simulations with identical initial and boundary conditions results in large variability in simulated cloud thickness and lifetime, ranging from rapid and complete glaciation of liquid to the production of long-lived, thick stratiform mixed-phase cloud.
\end{abstract}

\section{Introduction}

Aerosol effects on clouds are among the largest sources of uncertainty in understanding of future climate predictions (IPCC, 2007). Although numerous completed studies at- tempt to understand aerosol effects on liquid phase clouds (e.g. Jiang et al., 2006; Lu and Seinfeld, 2005; Menon et al., 2008), less attention has been given to similar interactions in mixed-phase clouds (e.g. Lohmann and Diehl, 2006). Stratiform mixed-phase clouds have been shown to commonly occur and impact the surface energy budget at high latitudes (e.g. de Boer et al., 2009; Shupe et al., 2006), and cloudinduced changes to the surface energy budget have been hypothesized to contribute in modulation of sea-ice extent (Kay et al., 2008).

In warm clouds, the so-called Twomey effect (a.k.a cloudalbedo effect, Twomey, 1977) results in an increase in cloud albedo for a cloud formed in aerosol-rich conditions (assuming comparable cloud water amounts) due to an increase in the number of nucleated liquid droplets. Additionally, cloud lifetime is thought to increase due to a reduction in the cloud's ability to precipitate (Albrecht, 1989). In mixedphase clouds, however, the scenario is more complicated as the phase of hydrometeors nucleated by aerosol particles also plays a large role in determining cloud albedo and lifetime. Studies completed by Harrington and Olsson (2001), Jiang et al. (2000) and others have illustrated strong sensitivity of stratiform mixed-phase cloud lifetime to the number of ice particles nucleated. This effect was attributed in part to the Wegener-Bergeron-Findeisen mechanism (Bergeron, 1935; Findeisen, 1938; Wegener, 1911), under which ice grows at the expense of liquid due to its lower saturation vapor pressure. Because of this favorable growth regime, water vapor is quickly used up when a significant number of ice particles 
are nucleated, resulting in rapid dissipation of the liquid portion of the cloud.

Because of this cloud lifetime dependence on nucleated particle phase, aerosol composition becomes a very important consideration. Generally, cloud condensation nuclei $(\mathrm{CCN})$ are water soluble and smaller than ice forming nuclei (IN). IN generally consist of insoluble material and feature chemical and structural characteristics favorable to ice formation (Pruppacher and Klett, 1997). Typical examples of IN include various types of mineral dust, bacteria and carbonaceous aerosol, while CCN often include sulfates, organics and sea salt. In addition, atmospheric aerosols serving as both IN and CCN exist. Often these are mixed particles, consisting of insoluble aerosol particles with soluble coatings, but studies have also been done to evaluate the CCN activity of aerosol particles such as sub micron mineral dust (e.g. Koehler et al., 2009).

Various IN result in ice formation via several primary nucleation mechanisms (Pruppacher and Klett, 1997). Deposition nucleation occurs on some traditional (insoluble) IN located in an environment that is supersaturated with respect to ice. Contact nucleation may occur on traditional IN or mixed aerosol particles, which come into contact with pre-existing water droplets resulting in the formation of an ice crystal. Mixed aerosol particles can additionally result in ice formation via the condensation and immersion freezing modes. In these ice formation mechanisms, aerosol particles containing a combination of soluble and insoluble material are situated in environments that are approaching or at water saturation. As water vapor begins to condense on the nucleus, one of two things can happen. The first is that the haze particle freezes before reaching critical size for formation of a liquid water droplet. This is generally considered to be condensation nucleation. The other possibility is that the aerosol particle can nucleate a liquid cloud droplet, which now contains an insoluble aerosol component. This droplet may later freeze, due to the ice nucleation abilities of that insoluble particle. It should be noted that mechanisms for freezing of droplets containing immersed IN are still under debate. Size dependent stochastic mechanisms, as used in this study, have been proposed by Bigg (1953) and others. Alternatively, the singular hypothesis (e.g. Levine, 1950) states that ice embryos form at a specific temperature for any given IN. While stochastic freezing is still temperature dependent, the change in temperature simply increases the likelihood of a particular droplet freezing, and does not guarantee it.

Studies have been completed analyzing possible nucleation mechanisms for different types of mixed-phase clouds. Diehl et al. (2006) investigated the effects of drop freezing in both the immersion and contact modes for a convective mixed-phase situation utilizing a parcel model. In this work, strong sensitivity to aerosol soluble mass and insoluble particle type were cited. The previously cited works of Harrington and Olsson (2001) and Jiang et al. (2000) demonstrated the influence of nucleation via deposition/condensation freez- ing on cloud lifetime. These results were strongly dependent upon the IN budget provided in the simulations and (in the case of Harrington and Olsson (2001)) whether IN were removed via precipitation or not. Khvorostyanov and Curry (2004) provided a theory on ice nucleation via "deliquescent-heterogeneous freezing" (DHF, similar to condensation freezing) at temperatures readily observed within the lower troposphere (approaching $0^{\circ} \mathrm{C}$ ). In part two of this work (Khvorostyanov and Curry, 2005), a parcel model was utilized to illustrate that ice nucleation via this mode can occur at water supersaturation when in the presence of liquid drops at temperatures as high as $-5^{\circ} \mathrm{C}$.

Whereas previous studies have focused on the influence of IN concentration on mixed-phase clouds, here we investigate the influence of both parameterized aerosol type and concentration on simulated mixed-phase stratiform cloud characteristics and lifetime. Several recent works (e.g. de Boer et al., 2010; Prenni et al., 2009; de Boer et al., 2011) demonstrate the possibility for an active immersion freezing regime within stratiform mixed-phase clouds. In de Boer et al. (2010), a conceptual model was presented illustrating the possible influence ice nucleation via the immersion mode could have on cloud lifetime. That investigation is expanded in the current work via analysis of the impact of aerosol properties on cloud liquid droplets, consequent immersion freezing and microphysical properties, and the resulting influences on cloud properties and lifetime. As in the work of Diehl et al. (2006), influences of aerosol soluble mass fraction and insoluble mass type are investigated. However, unlike in that work, experiments are carried out utilizing twodimensional, cloud-resolving simulations of a mixed-phase stratiform layer in order to analyze the ultimate influence of aerosol properties on both cloud micro- and macrophysics.

\section{Model description}

High resolution two-dimensional numerical simulations were completed utilizing the University of Wisconsin NonHydrostatic Modeling System (UW-NMS, Tripoli, 1992). While there are potential advantages to three-dimensional simulation (e.g. Bretherton et al., 1999), the complexity of the current microphysical scheme make this an impractical option for running a relatively large number of sensitivity experiments as done here. The UW-NMS was designed as a fully scalable mesoscale model, capable of cloud-scale simulation. The formulation of the NMS is enstrophy-conserving and utilizes a quasi-compressible closure formulated in the non-Boussinesq framework. Simulations were completed using long and shortwave rapid radiative transfer models from Atmospheric and Environment Research Inc. (AER, Clough et al., 2005). 


\subsection{The Advanced Microphysical Prediction System}

For simulations discussed in this work, a bin microphysical scheme is utilized. The Advanced Microphysical Prediction System (AMPS, Hashino and Tripoli, 2007) is composed of several components. Liquid microphysics is handled by the Spectral LIquid Prediction System (SLIPS), aerosol microphysics by the Aerosol Prediction System (APS) and ice phase microphysics by the Spectral Ice Habit Prediction System (SHIPS). As with other spectral bin models, AMPS explicitly evolves mass spectra for ice and liquid hydrometeors in a way that bin number concentration and mass are conserved. Each bin has a sub-distribution, represented as a linear function of mass. The slope and intercept of the subdistribution are determined by predicted number concentration and mass content of individual bins.

SliPS simulates vapor deposition, collision-coalescence and collision-breakup processes for the liquid phase. This is handled in a mass-based bin method, with prognostic variables including concentration and mass content. Forty mass bins were utilized in a non-linear fashion to cover droplet sizes between $0.1 \mu \mathrm{m}$ and $5 \mathrm{~mm}$. Liquid particle property variables (PPVs) predicted include aerosol mass content and aerosol soluble mass content.

The APS predicts two types of aerosols. Purely insoluble aerosols are considered to be IN while mixed aerosol particles, consisting of both soluble and insoluble mass are considered condensation nuclei (CN). Aitken and accumulation mode $\mathrm{CN}$ are simulated using two lognormal distributions, while IN are simulated with a monodisperse distribution. In these simulations, processes related to IN, as described here, are turned off, meaning that $\mathrm{CN}$ are responsible for the formation of liquid droplets and eventual freezing of these droplets. As with SliPS, APS predicts concentration and mass content, along with the PPV soluble mass content. $\mathrm{CN}$ are only removed through cloud droplet activation, a process that is allowed to continue as long as cloud is present in a given grid box, as determined by droplet concentration $\left(>1 \mathrm{~cm}^{-3}\right)$ and mean droplet size $(>1 \mu \mathrm{m})$. The $\mathrm{CN}$ distribution for a cloudless grid box is fixed to the bimodal lognormal distribution described in Sect. 3. In this version, dry $\mathrm{CN}$ are activated according to the Köhler curve for mixed aerosol particles and transferred to the liquid spectrum at the critical radius. Mass and number concentration of activated droplets are determined based on supersaturation diagnosis. First, the lognormal distribution of each mode of the dry CN spectrum is divided into ten discrete mass bins, and a critical supersaturation is calculated for each one. If the critical supersaturation is smaller than the supersaturation resulting from dynamics, then aerosol particles in that mass bin can be activated during the microphysical time step. Secondly, the amount of water used for the dry $\mathrm{CN}$ to grow to the critical size droplets is calculated for the mass bins in which at least some particles will be activated, which is subsequently used to calculate the maximum supersaturation required to grow all the dry $\mathrm{CN}$ in that bin $\left(S_{\max }\right)$. The ratio of the supersaturation at the end of time step s $(t+\Delta t)$ to $S_{\max }$ is assumed to be the fraction of dry $\mathrm{CN}$ to be activated from a given bin. The number concentration of activated droplets is calculated by multiplying this fraction to the number concentration of the bins experiencing at least some activation. $\mathrm{s}(\mathrm{t}+\Delta \mathrm{t})$ is iteratively calculated by solving implicit finite difference equations for liquid and ice mixing ratios including microphysical sources and sinks, similar to Walko et al. (2000).

In our simulations, SHIPS simulates the ice phase utilizing 20 mass bins, predicting 16 distinct PPVs per bin. A unique aspect of SHIPS is that the ice model makes no apriori assumption of ice characteristics such as habit, size and density. This is a key innovation because it allows ice habits to evolve as a function of particle history. This results in an infinite number of habit configurations and overcomes a long-standing shortcoming of previous ice microphysics parameterizations that simulate the variability of ice habit only through the formation of a few specific ice categories such as "cloud ice", "graupel", "snow". The problem with the traditional approach is that particle evolutionary history is only portrayed via pre-defined pathways and state transitions. This makes it very difficult to formulate inter-habit conversion rates as well as capture evolutionary subtleties within habits. In SHIPS, PPVs for each bin are advected with that ice mass throughout the cloud. These variables include ice crystal mass produced by depositional growth, length of a, c, and dendritic axes of an hexagonal crystal, produced riming mass, and particle maximum dimension. Quantities such as growth rate, fall velocity, collision and collection efficiency depend on these evolving ice characteristics. Then, at any point, these evolved parameters can be utilized to diagnose ice particle habits for any bin (i.e. dendrite, plate, column, rosette, aggregate, low-density graupel, hail, etc.) and simulated differences due solely to habit assignment such as those presented in Avramov and Harrington (2010) are avoided.

For simulations discussed here, only the immersion freezing mode of nucleation is considered. Immersion freezing is represented using the stochastic hypothesis from Bigg (1953), and has been updated to include solubility effects in droplets after Diehl and Wurzler (2004). In this implementation, for pure water droplets of similar sizes containing insoluble particles, the number of droplets freezing during a given timestep is given by:

$N_{f l}^{b}=N_{l}^{b}\left[1-\exp \left(\frac{-\bar{m}_{l}^{b}}{\rho_{\mathrm{w}}} B_{h, i} \exp \left(a\left[T_{0}-T+\Delta T_{\mathrm{f}}\right]\right) \Delta t\right)\right]$

where $N_{f l}^{b}$ is the number of frozen droplets in the $\mathrm{b}^{t h}$ bin of the liquid hydrometeor mass spectrum, $N_{l}^{b}$ the number of unfrozen droplets, $\bar{m}_{l}^{b}$ is the mean mass of the $\mathrm{b}^{\text {th }}$ bin, $T$ the temperature in ${ }^{\circ} \mathrm{C}, T_{0}$ a reference temperature, $\Delta T_{\mathrm{f}}$ the freezing point depression due to soluble material, $\rho_{\mathrm{w}}$ the density of water, $\Delta t$ the microphysics timestep, and $a$ and $B_{h, i}$ laboratory-derived constants (see Table 1). $B_{h, i}$ represents 
Table 1. Values for the freezing calculation constants (particle values from Diehl and Wurzler, 2004).

\begin{tabular}{lll}
\hline Aerosol Characterization & $\mathrm{a}\left(\mathrm{K}^{-1}\right)$ & $\mathrm{B}_{h, i}\left(\mathrm{~cm}^{-1} \mathrm{~s}^{-1}\right)$ \\
\hline Kaolinite & 1 & $6.15 \times 10^{-8}$ \\
Illite & 1 & $6.19 \times 10^{-5}$ \\
Montmorillonite & 1 & $3.23 \times 10^{-5}$ \\
Soot & 1 & $2.91 \times 10^{-9}$ \\
Bigg & 0.66 & $1 \times 10^{-4}$ \\
\hline
\end{tabular}

the freezing efficiency in the immersion mode of an insoluble particle type, per unit volume of liquid. Immersion freezing acts as a sink for liquid hydrometeors. It should be noted that a limitation of applying this particular calculation to a model framework is that it is not possible to account for prolonged supercooling of droplets beyond the model microphysical time step. In reality, the number of droplets freezing at any given time includes a fraction of droplets that have been exposed to supercooled conditions for a prolonged period of time.

\subsection{Sensitivity of applied immersion freezing parameterization}

To assess the largest contributing factors to changes in ice particle production due to immersion freezing, simple tests were completed for the parameterization described in Eq. (1). This expression can be simplified to:

$F_{\text {freeze }}=1-\exp (-\exp (Y))$

where $F_{\text {freeze }}$ is the fraction of liquid droplets frozen, and $Y$ is defined as:

$Y=\ln \left(B_{h, i}\right)+\ln \left(\mathrm{V}_{\mathrm{d}}\right)+a \Delta T_{\mathrm{a}}+a \Delta T_{\mathrm{f}}+\ln (\Delta t)$

where $\mathrm{V}_{\mathrm{d}}$ is the droplet volume, and $\Delta T_{\mathrm{a}}$ is the air temperature offset from the freezing point, which is equal to $T_{0}-T$ in Eq. (1). The individual contributions of terms on the right hand side of Eq. (3) to $Y$ are obtained using a parcel model, and illustrated in Fig. 1. Since larger $Y$ values lead to larger freezing fractions, this figure demonstrates that for all but the smallest droplets, freezing point depression (greyscale lines) does not influence droplet freezing (contribution to $Y$ equals zero). Conversely the freezing efficiency of the insoluble material involved (contributions to $Y$ demonstrated by red, green, blue and purple lines) always contributes negatively to $Y$, meaning that freezing efficiency plays a more significant role in determining whether droplets freeze than the soluble portion-induced freezing point depression. Since the vast majority of aerosol particles included in the simulations discussed in this work are smaller than $3 \mu \mathrm{m}$, droplets larger than $5 \mu \mathrm{m}$ do not see appreciable inhibition to freezing from aerosol-induced freezing point depression. At even smaller aerosol sizes (e.g. $1 \mu \mathrm{m}, 0.6 \mu \mathrm{m}$ and $0.3 \mu \mathrm{m}$ ), this critical droplet size decreases even further $(2 \mu \mathrm{m}, 1.5 \mu \mathrm{m}$ and $0.8 \mu \mathrm{m}$, respectively). Additionally, $Y$ is demonstrated to increase with droplet volume (orange line), resulting in higher freezing fractions for larger droplets. Finally, the influence of the freezing efficiency term $\left(\mathrm{B}_{h, i}\right.$, colored lines) is demonstrated, with the four order of magnitude change from Montmorillonite to Soot resulting in a contribution to $\mathrm{Y}$ roughly equivalent to a warming of $10^{\circ} \mathrm{C}$. Of course, when applied to a realistic atmosphere, the contributions due to temperature, droplet volume and freezing point depression are highly variable within the cloud, and competing and complementary interactions between these sensitivities as simulated for a mixed-phase stratiform scenario are discussed in the following sections.

\section{Simulation overview}

The mixed-phase stratiform cloud case selected for simulation was observed at the Surface Heat Budget of the Arctic campaign (SHEBA, Uttal et al., 2002) site on 7-8 May 1998. This case was chosen in part due to its selection for the recently completed Global Energy and Water Cycle Experiment (GEWEX) Cloud System Study (GCSS)/World Meteorological Organization (WMO) model intercomparison, aimed at improving our understanding of the effects of ice nucleation in simulation of mixed-phase clouds (Morrison et al., 2011). The simulated cloud represents part of a persistent mixed-phase stratiform layer that occurred at SHEBA from 1-18 May. The synoptic scale pattern for the 7-8 May time period was characterized by a broad region of anticyclonic circulation centered above the SHEBA site. The National Centers for Environmental Prediction (NCEP) reanalysis reveals general subsidence, with an $850-\mathrm{hPa}$ vertical pressure velocity of about $1 \mathrm{hPa}$ per hour. The boundary layer height was decreasing in response to the strengthening anticyclone.

A comprehensive set of aircraft and ground-based instrumentation was used to determine cloud characteristics. Cloud temperatures between 253-256 K were reported. Liquid water contents from the Forward Scattering Spectrometer (FSSP) and King probes ranged from around $0.01 \mathrm{~g} \mathrm{~m}^{-3}$ to approximately $0.06 \mathrm{~g} \mathrm{~m}^{-3}$. Liquid water paths were very small, ranging from 10 to $35 \mathrm{~g} \mathrm{~m}^{-2}$. Ice concentrations, as determined by the 2DC and 2DP probes ranged from near zero to around $20 \mathrm{~L}^{-1}$, with a mean value of $1.44 \mathrm{~L}^{-1}$ below cloud, and $0.75 \mathrm{~L}^{-1}$ within the mixed-phase layer.

An idealized atmospheric sounding was provided for model initialization (Fig. 2). In addition, large-scale forcings were derived from an analysis of European Centre for Medium-Range Weather Forecasts (ECMWF) model data. Included were large-scale horizontal advective tendencies of temperature and water vapor. These tendencies are applied continuously over the 12-h simulation period. Surface fluxes 
Table 2. An overview of simulations completed in this study.

\begin{tabular}{llll}
\hline Simulation & Insoluble Type & $\begin{array}{l}\text { Soluble Mass } \\
\text { Fraction }\end{array}$ & $\begin{array}{l}\text { Extra } \\
\text { Description }\end{array}$ \\
\hline NOICE & Kaolinite & $70 \%$ & $\begin{array}{l}\text { No active ice nucleation } \\
\text { mechanisms }\end{array}$ \\
KAO & Kaolinite & $70 \%$ & \\
ILL & Illite & $70 \%$ & \\
MON & Montmorillonite & $70 \%$ & \\
SOO & Soot & $70 \%$ & \\
BIG & Bigg Parameterization & $70 \%$ & \\
K30 & Kaolinite & $30 \%$ & \\
K50 & Kaolinite & $50 \%$ & \\
K95 & Kaolinite & $95 \%$ & \\
S30 & Soot & $30 \%$ & \\
S50 & Soot & $50 \%$ & $72.2 \mathrm{~cm}^{-3}$ CN \\
S95 & Soot & $95 \%$ & $650 \mathrm{~cm}^{-3} \mathrm{CN}$ \\
KLO & Kaolinite & $70 \%$ & No Freezing Point Depression \\
KHI & Kaolinite & $70 \%$ & No Freezing Point Depression \\
KNFPD & Kaolinite & $70 \%$ & \\
SNFPD & Soot & $70 \%$ & \\
\hline
\end{tabular}

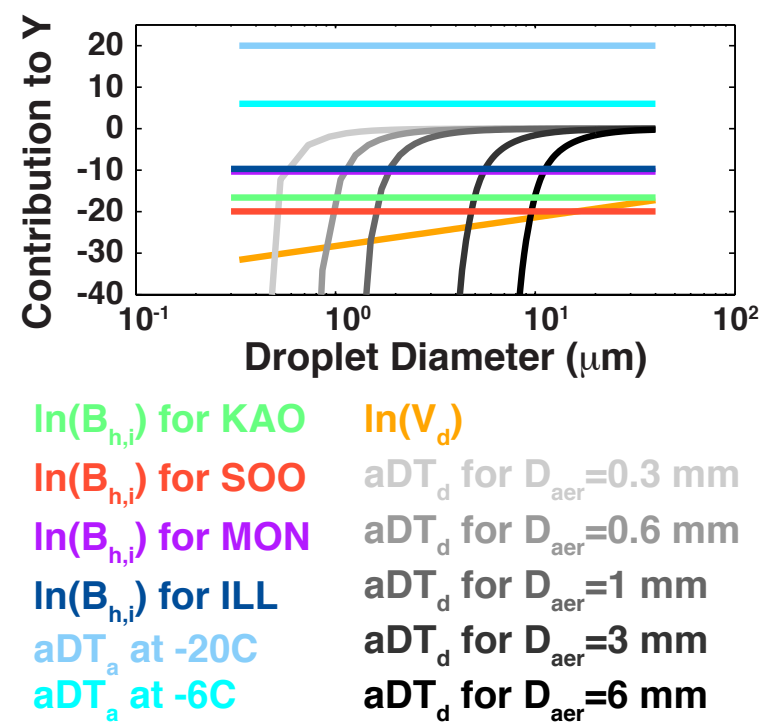

Fig. 1. Contributions of individual components of Eq. (3) for different sized liquid droplets. Included are contributions to $\mathrm{Y}$ from $\ln \left(B_{h, i}\right)$ for aerosols of various compositions (KAO, SOO, MON and ILL), a $\Delta T_{\mathrm{a}}$ for $-20^{\circ} \mathrm{C}$ and $-6^{\circ} \mathrm{C}, \ln \left(\mathrm{V}_{\mathrm{d}}\right)$, and $\mathrm{a} \Delta T_{\mathrm{d}}$ (freezing point depression) for droplets formed on aerosol particles with different dry sizes (greyscale lines).

were specified to the ECMWF values of $7.98 \mathrm{Wm}^{-2}$ for sensible heat and $2.86 \mathrm{Wm}^{-2}$ for latent heat.

Aerosol specifications were given based on measurements described in Yum and Hudson (2001). The CN size distribution was assumed to follow a bimodal lognormal size distri-
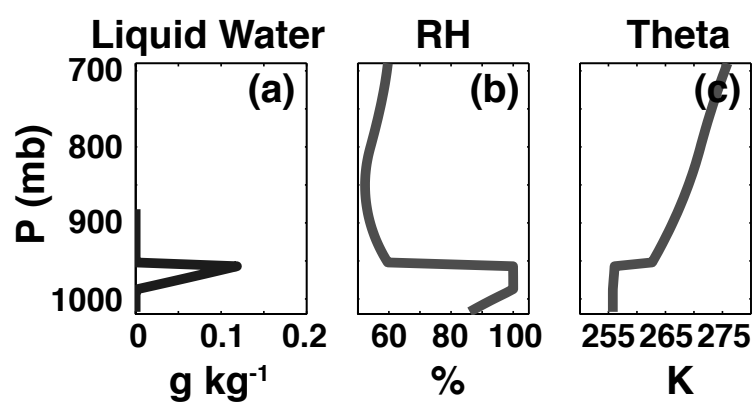

Fig. 2. Profiles of cloud liquid water (a), relative humidity (b) and potential temperature (c) used for the 7-8 May simulations (from Morrison and Zuidema, 2008).

bution, with each mode given by:

$\frac{d N}{d \ln (r)}=\frac{N_{\mathrm{t}}}{\sqrt{2 \pi} \ln (\sigma)} \exp \left[\frac{\ln ^{2}\left(r / r_{\mathrm{m}}\right)}{2 \ln ^{2} \sigma}\right]$

where $\sigma, r_{\mathrm{m}}$ and $N_{\mathrm{t}}$ are the standard deviation, geometric mean and total number concentration of each mode, respectively. These parameters for the Aitken (accumulation/coarse) mode were determined to be $2.04,0.052 \mu \mathrm{m}$ and $350 \mathrm{~cm}^{-3}\left(2.5,1.3 \mu \mathrm{m}\right.$ and $\left.1.8 \mathrm{~cm}^{-3}\right)$, respectively. CN soluble mass was assumed to consist of ammonium bisulfate with varied soluble mass fractions.

Simulations completed include a variety of sensitivity experiments testing the effect of parameterized aerosol properties on simulated clouds (Table 2). Generally, $70 \%$ was used as a baseline soluble mass fraction when testing the effect of insoluble mass type based on work done by Bigg and Leck (2001) and Zhou et al. (2001). Assuming 70\% soluble 
mass fraction, the influence of insoluble mass type was analyzed by varying the insoluble particle type between Kaolinite (KAO), Illite (ILL), Montmorillonite (MON) and Soot (SOO). The freezing efficiencies of these particle types are characterized within the immersion freezing parameterization using constants $\left(\mathrm{B}_{h, i}\right)$ from Diehl and Wurzler (2004) who derived them from laboratory experiments. It is important to note that the coefficients used in the current study only represent the results of one study, and other efforts have been made to characterize the freezing efficiency of these and other aerosol types (e.g. Broadley et al., 2012; Zimmerman et al., 2008). In addition, several simulations were completed to investigate the effect of aerosol soluble mass fraction on immersion freezing and cloud lifetime. Using both Kaolinite and Soot as insoluble mass types, we completed simulations featuring $30 \%, 50 \%, 70 \%$ and $95 \%$ (K30, K50, KAO, K95, S30, S50, SOO and S95) soluble content by mass. Additionally, we completed simulations using Kaolinite and the Bigg formulation to assess the impact of a calculated freezing point depression due to the soluble mass. This was done by including and removing the freezing point depression when calculating freezing temperature. Finally, we evaluated the impact of aerosol concentration. Simulations were completed with initial particle concentrations of $72.2 \mathrm{~cm}^{-3}$ (value from the Mixed-Phase Arctic Clouds Experiment), $350 \mathrm{~cm}^{-3}$ (value from SHEBA) and $650 \mathrm{~cm}^{-3}$ (extreme pollution case).

All simulations were completed on a $5400 \mathrm{~m}$ horizontal domain with $100 \mathrm{~m}$ horizontal grid spacing. Vertical grid spacing is variable, with $25 \mathrm{~m}$ spacing up to $500 \mathrm{~m}$, increasing by $110 \%$ to a maximum vertical spacing of $250 \mathrm{~m}$, with the top of the domain at $4184 \mathrm{~m}$. The simulations utilized a 2 second temporal resolution for dynamical calculations, a 0.5 second time step for microphysical processes and a 120 second time step for radiation.

\section{Results}

\subsection{Warm and reference cases}

The KAO (Kaolinite with $70 \%$ soluble mass) and NOICE (no active ice microhysics) simulations were chosen as reference simulations. Figure 3 shows the domain mean cloud water mixing ratio as a function of time for these two simulations (a, b). Additionally, the domain average liquid (LWP) and ice (IWP) water paths are shown (c, d), with observations included as black dots with grey shading. Please note that the zero IWP observed for the first few hours of this period is the result of instrument downtime and do not reflect a lack of snow during this time period. Both simulations maintain some liquid water throughout the twelve hour period, with the Kaolinite simulation losing liquid water with nucleation and growth of ice crystals. The amount of water is modulated by a large-scale advective tendency prescribed

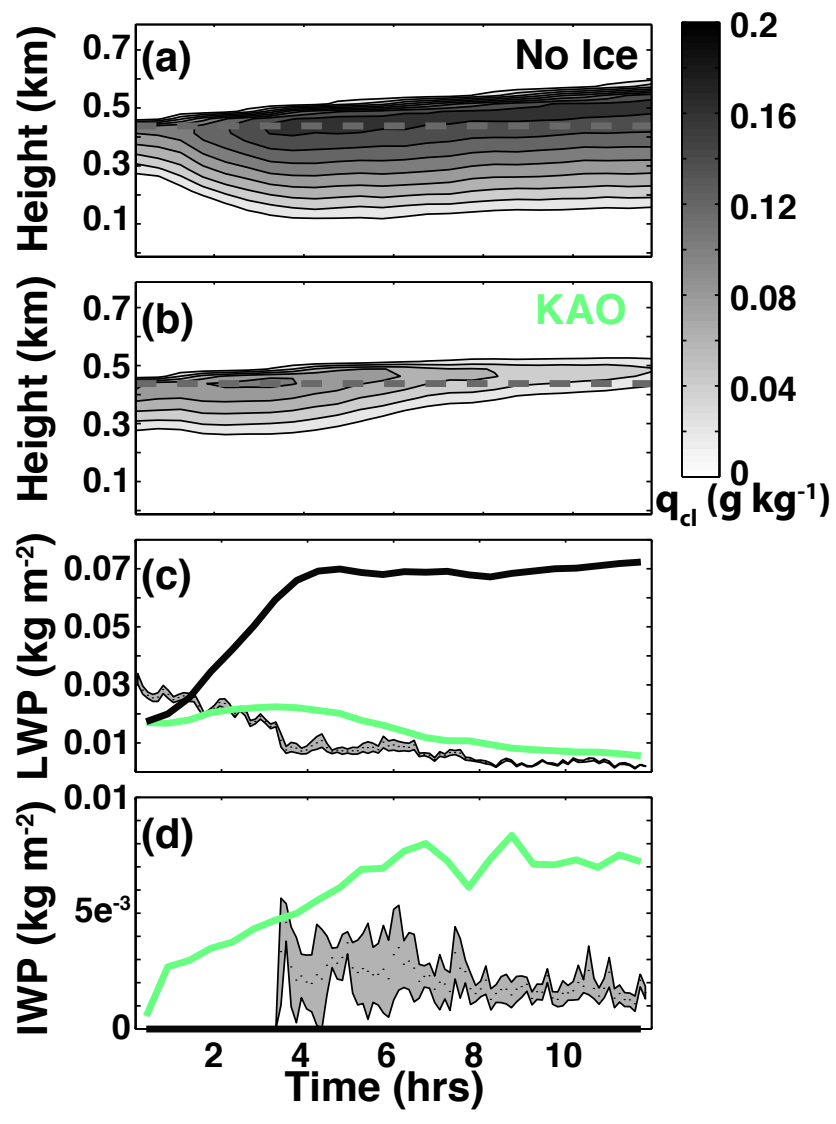

Fig. 3. Domain-averaged time-height cross-sections of cloud liquid water mixing ratio $\left(\mathrm{g} \mathrm{kg}^{-1}\right)(\mathbf{a}, \mathbf{b})$ and timeseries of domainaveraged liquid (c) and ice water paths (d) for the reference simulations (NOICE, black and KAO, green). The dashed line on the mixing ratio figures is included to provide a reference height. Observed estimates for liquid and ice water path are shown in black dots (mean) and grey shading (standard deviation).

for the intercomparison to match observations, and by depositional growth of hydrometeors. Because nucleated ice crystals grow rapidly via the Wegener-Bergeron-Findeisen effect, they will strongly influence the amount of water vapor present, thereby controlling liquid water amount. Despite overestimating IWP relative to observations, the KAO simulation features LWP values close to those observed over the course of the twelve hour simulation. Without the iceinduced liquid water sink, the NOICE simulation has a LWP that is an order of magnitude larger than observed by the end of the simulation period. Domain-averaged condensational growth tendencies of ice crystals for the KAO simulation (not shown) range from 0.006 to $0.01 \mathrm{~g} \mathrm{~m}^{-3} \mathrm{~h}^{-1}$, roughly an order of magnitude larger than liquid removed via riming $(0.0005$ to $0.0015 \mathrm{~g} \mathrm{~m}^{-3} \mathrm{~h}^{-1}$ ), demonstrating the relative efficiency of removal of water vapor and liquid water via the WegenerBergeron-Findeisen process. 


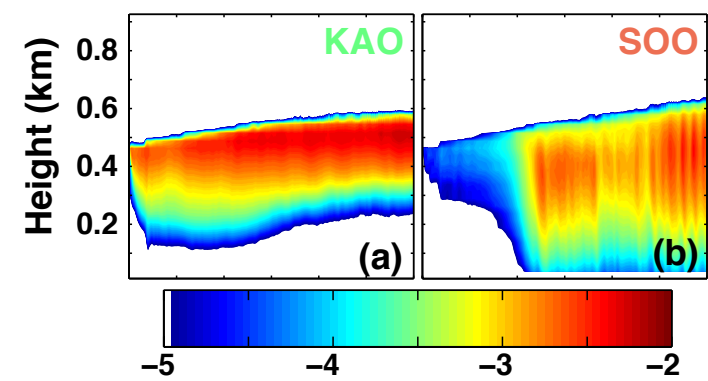

Freezing Rate $\left(\log _{10}\left(\mathrm{~g} \mathrm{~kg}^{-1} \mathrm{day}^{-1}\right)\right)$

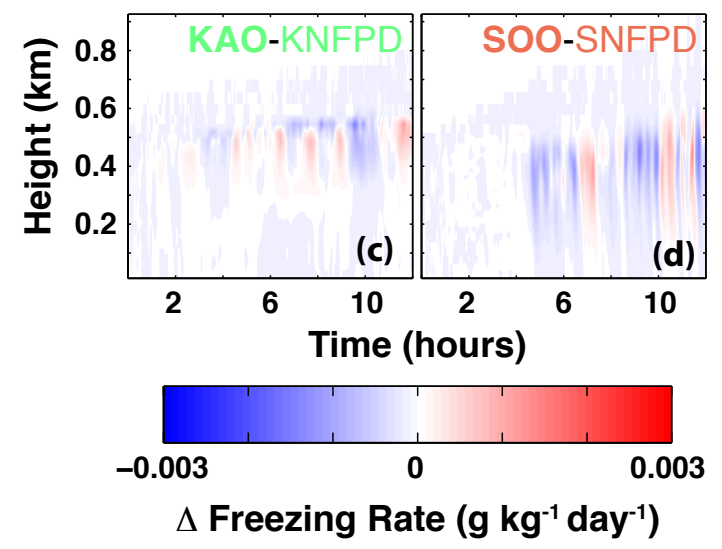

Fig. 4. Domain-averaged time-height cross-sections of immersion freezing rates from the KAO (a) and SOO (b) simulations, and the differences between the domain-averaged rates from those simulations and those from the KNFPD (c) and SNFPD (d) (without freezing point depression) simulations.

\subsection{Impact of aerosol-induced freezing point depression}

Hypothesized by de Boer et al. (2010) to be a mechanism for limiting droplet freezing within mixed-phase stratiform clouds, the freezing point depression induced by soluble material within droplets is an important process included in this evaluation. Figure 4 demonstrates the different immersion freezing rates between simulations in which the freezing point depression was calculated (KAO, SOO) and those in which the aerosol-induced freezing point depression was not applied (KNFPD, SNFPD). Generally the differences are small, and as demonstrated in Figs. 11 and 15, the differences resulting from eliminating the freezing point depression are smaller than those resulting from variation of other aerosol properties. Differences that do exist are generally as may be expected, with simulations in which the freezing point depression was not included having higher freezing rates than those where it was. These results, combined with calculations of the freezing point depression term $\left(\Delta T_{\mathrm{d}}\right.$ in Eq. (3)) and critical radii of formation for liquid droplets under the given conditions (not shown) indicate that the impact of aerosolinduced freezing point depression is of second order when compared to the other terms in Eq. (3). Having said this, this effect becomes much more relevant for haze droplets, limit- ing the amount of nucleation via the condensation mode and the amount of ice nucleated at low levels in the cloud (here defined as the lowest portions of the region containing supercooled liquid). Unfortunately, the freezing of sub-critical droplets is not considered in this version of AMPS, and is therefore not reviewed here. Based on this analysis it is determined that while the liquid-limited ice nucleation pathways maintaining mixed-phase stratiform clouds as proposed in de Boer et al. (2010) remain interesting, droplet freezing point depression is unlikely to be the limiting factor in the freezing of super-critical liquid cloud droplets. Because of this, the $\Delta T_{\mathrm{d}}$ term is omitted from discussion in the following sections.

\subsection{Variation of the insoluble mass type}

In order to understand the impact of different insoluble mass types on immersion freezing within mixed-phase clouds, the influence of this change on the terms of Eq. (3) is performed. The structures of different substances impact their ability to nucleate ice crystals (e.g. Fukuta, 1958; Roberts and Hallett, 1968). Certainly $B_{h, i}$, the freezing efficiency term that reflects these differences, is variable between insoluble mass types, with Soot having the lowest theoretical freezing efficiency of the materials evaluated here and Illite having the highest. It should be noted that although coefficients for specific aerosol types based on lab measurements were used here, this analysis could be thought of for a spectrum of particle freezing efficiencies, without specific identification of aerosol composition. Because model aerosol composition is defined by mass, initial differences in the magnitude of aerosol soluble mass due to differences in the density of the insoluble component are present, but small. Because of this, significant differences in initial droplet growth rates are not expected. However, differences in freezing rates, and the related modulation of local relative humidity and subsequent droplet growth/evaporation can result in variability of $\Delta T_{\mathrm{a}}$, the atmospheric temperature. These differences in relative humidity can also result in droplet volume variability, directly impacting the simulated freezing rate.

Temporal evolution of quantities impacting the amount of immersion freezing is shown in Fig. 5a, along with distributions of droplet volume (Fig. 5b) and temperatures (Fig. 5c) at the top of the cloud (defined as the highest point with $\left.q_{\mathrm{cl}}>1 \times 10^{-8} \mathrm{~g} \mathrm{~kg}^{-1}\right)$. Because most of the liquid water in the MON and ILL simulations is rapidly glaciated, droplet sizes stay very small, and the lines indicating the sum of contributions to the droplet freezing rate (Fig. 5a) sporadically do not exist. Generally, the freezing efficiency term $\left(\mathrm{B}_{h, i}\right)$ is demonstrated to be the most influential aerosol property (triangles in Fig. 5a). Droplet volume does vary between simulations, with volumes generally larger in simulations where the insoluble aerosol component is less efficient at nucleating ice. Distributions depicting all cloud-top droplet volumes at various times in the simulation (Fig.5b) 

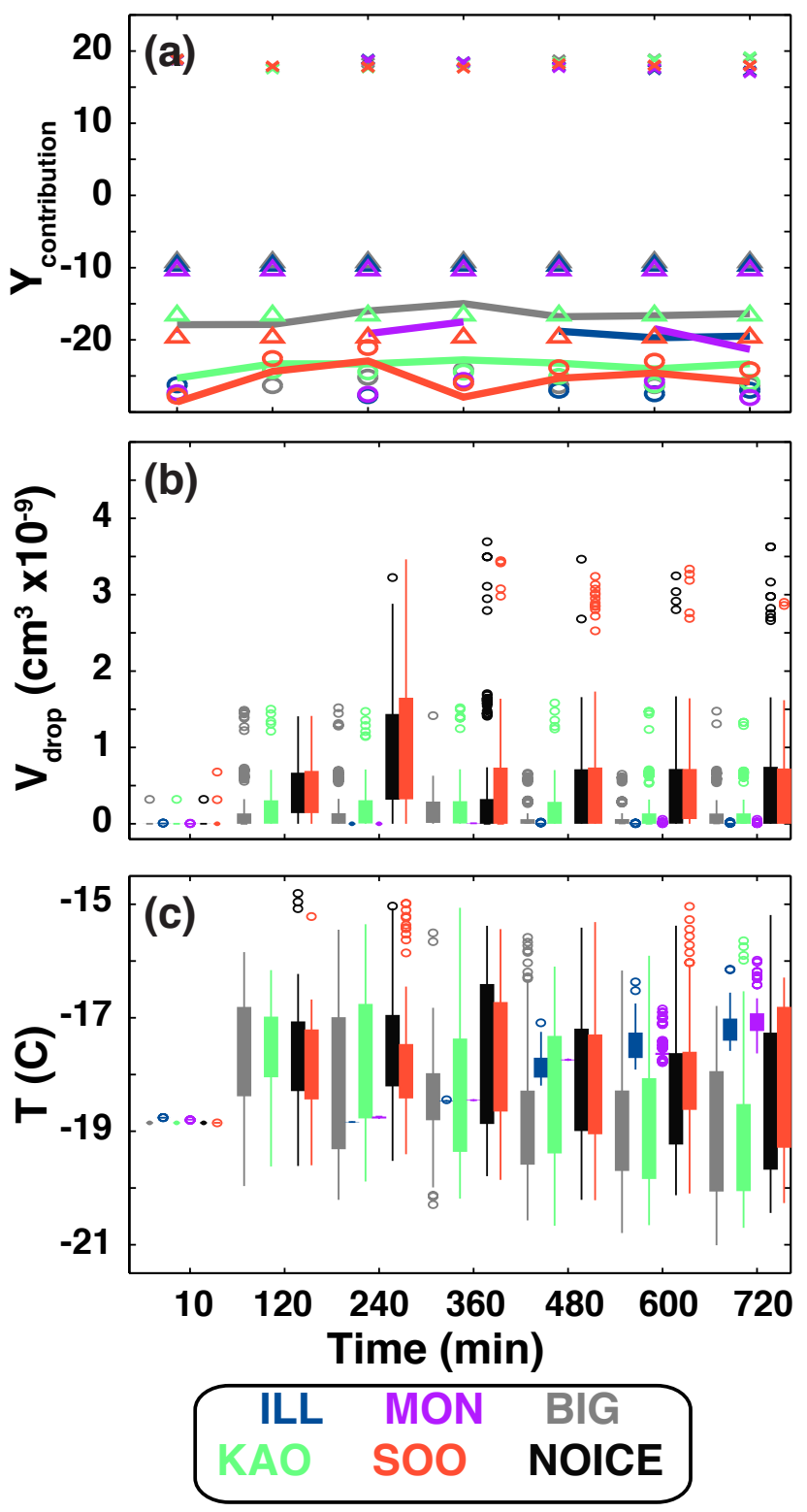

Fig. 5. Contributions to the immersion freezing parameterization plotted versus time. (a) demonstrates contributions from temperature (x's), particle freezing efficiency ( $\mathrm{B}_{h, i}$, triangles), and droplet volume (circles). The lines are the sum of these three terms (NOICE line and markers are not included). (b) provides distributions of droplet volume for at cloud top as determined using a cloud water mixing ratio threshold, and (c) shows temperature distributions for the same altitude.

demonstrate that ice formation results in a narrowing of the spectrum of simulated droplet volumes, with both the KAO and BIG simulations having smaller and narrower distributions than SOO and NOICE. Interestingly, SOO maintains larger droplets than the NOICE simulation. An analysis of the vapor/precipitation budget (not shown) reveals that relative to the NOICE simulation, rain formation is reduced in the SOO simulation due to the freezing of the largest droplets. Although this introduces ice crystals into the domain, there are relatively few of these, and their growth is vapor dependent, whereas the growth of the rain droplets is both vapor dependent and through collision/coalescence processes. The amount of water mass removed via the rain process is larger than that removed by snow for the SOO simulation, since only a small amount of ice is nucleated. Therefore, a reduction in rain production allows more of the liquid to remain within the cloud layer, resulting in a larger overall liquid water path over time. Toward the end of the 12 hour simulation period, however, ice production increases due to the gradual increase in mean droplet size, resulting in an increased sink of vapor, and a gradual thinning of the cloud layer. Additionally, this discrepancy in the rain production can partially be traced back to the above discussion on originally assumed aerosol chemistry. Since bulk density of the assumed soluble material (in this case $\mathrm{NH}_{4} \mathrm{HSO}_{4}$ ) is constant, a calculation of total soluble mass is a function of both the aerosol particle size (constant governed by size distribution) and the bulk density of the insoluble material. Since the NOICE simulation assumes Kaolinite as the insoluble material, this results in the Soot-containing aerosol particles having a slightly different amount of soluble material (despite having a consistent soluble mass fraction), impacting liquid droplet growth and nucleation rates later in the simulation.

Figure 6 provides an overview of cloud macrophysical characteristics from the five simulations completed for different insoluble mass types and the Bigg formulation (KAO, ILL, MON, SOO, BIG) as well as the warm microphysics only case (NOICE). The figure's two upper rows present mean cloud liquid water mixing ratio versus height and time. As mentioned above, ILL and MON rapidly glaciate, removing cloud liquid water from the simulation. The influence of the freezing efficiency term contribution to calculating the immersion freezing rate is evident in the cloud water mixing ratio plots, with the amount of cloud water scaling to that term. Simulated liquid and ice water paths (third and fourth rows) demonstrate this as well, and also show that SOO LWP is higher than that of NOICE later in the simulation. For LWP, most simulations are above the measured quantities (demonstrated by grey shading), though the BIG and $\mathrm{KAO}$ simulations are not far off. Ice is a different story, with KAO and BIG over-simulating the IWP, and SOO undersimulating it.

Differences in the cloud liquid water have significant implications on the surface radiative budget (Fig. 6i, j). The ILL and MON simulations, which rapidly lose cloud liquid have greatly reduced downwelling longwave radiation, and a large increase in the downwelling shortwave radiation. Similar patterns are demonstrated with the other simulations, with increases in surface downwelling longwave and decreases in downwelling shortwave correlated to the amount of ice produced and its impact on the liquid portion of the cloud. The relative importance of the impacts on short and longwave 

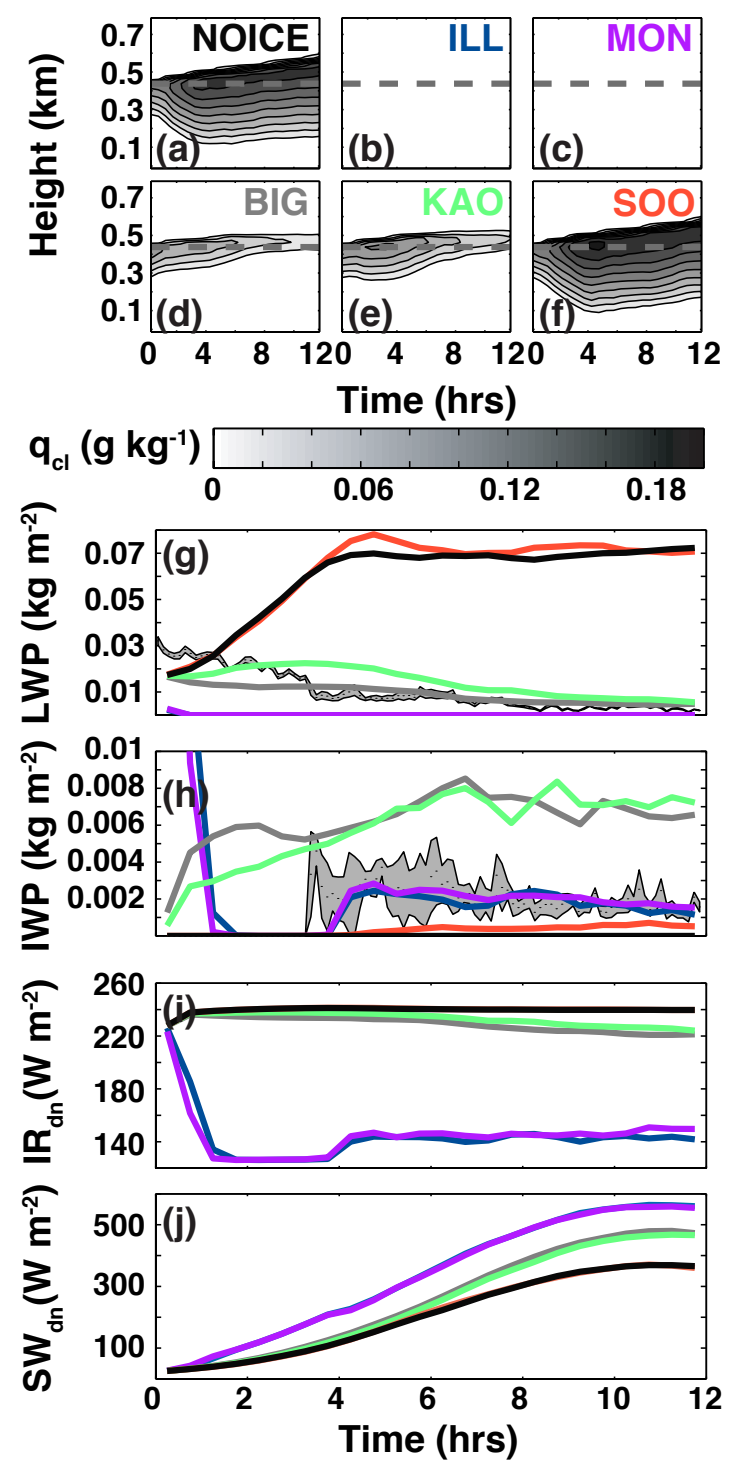

Fig. 6. An overview of simulation results assuming different insoluble mass types. Included are domain-averaged time-height crosssections of cloud water mixing ratio (a-f), and time series of domain-averaged liquid water path (g) ice water path (h), surface downwelling longwave radiation (i), and surface downwelling shortwave radiation (j). Grey shading in the liquid and ice water path plots represent the mean \pm one standard deviation of observed values.

radiation are season dependent, with longwave effects most influential during the Arctic winter, and the shortwave effects most influential during summer months featuring 24-h of sunlight.

Figure 7 illustrates differences in mean microphysical tendencies for the second six hours of the simulation period. These tendencies do not constitute a complete budget of any sort, but are selected to highlight specific processes and features of the cloud system. The liquid condensation tendency (not shown) reveals that all simulations except MON and ILL

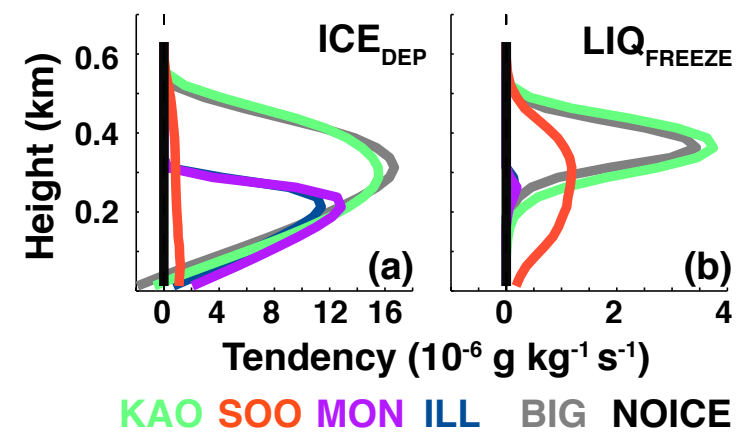

Fig. 7. Vertical profiles of domain-averaged microphysical tendencies for the second half of the $12 \mathrm{~h}$ simulation period from simulations featuring different insoluble mass types (color coded at bottom). Included are profiles of ice depositional growth tendency (a) and liquid freezing tendency (b).

have comparable amounts of liquid formation at cloud top. The SOO and NOICE simulations feature thicker liquid layers than those in the BIG and KAO runs, impacting the vertical distribution of droplet freezing (Fig. 7b), with the droplets in the SOO simulation freezing between the top of the cloud $(600 \mathrm{~m})$ and the surface. However, the impact of the insoluble mass freezing efficiency results in freezing rates in the SOO simulation that are less than half of those in the KAO and BIG simulations. It is interesting to note that while the column-integrated droplet freezing tendency is only slightly different between the KAO, BIGG and SOO simulations, the number of ice crystals involved and the concentration of that mass at higher altitudes results in a much higher amount of ice depositional growth (Fig. 7a) in the KAO and BIGG simulations. This process results in the large discrepancies in the ice water paths shown in Fig. 6. With the large amount of ice growing within and below the clouds, the total microphysical vapor tendency (not shown) for the BIG and KAO simulations is negative from cloud top down. In contrast, the SOO simulation demonstrates a strongly negative vapor tendency near cloud top (due to increased concentrations of liquid droplets and stronger radiative cooling and associated circulations), but only slightly negative total vapor tendencies below that region.

\subsection{Variation of the soluble mass fraction}

Comparisons were completed between KAO30, KAO50, KAO, KAO95 and KNFPD and between SOO30, SOO50, SOO, SOO95 and SNFPD respectively in order to evaluate the impact of aerosol soluble mass fraction on immersion freezing. The comparison was done for both Kaolinite and Soot simulations in order to verify whether the freezing efficiency of the aerosol insoluble mass component influenced the perceived impact of soluble mass fraction. Because it does not appear that aerosol soluble mass does much to prevent freezing in supercritical droplets, the main impacts on 

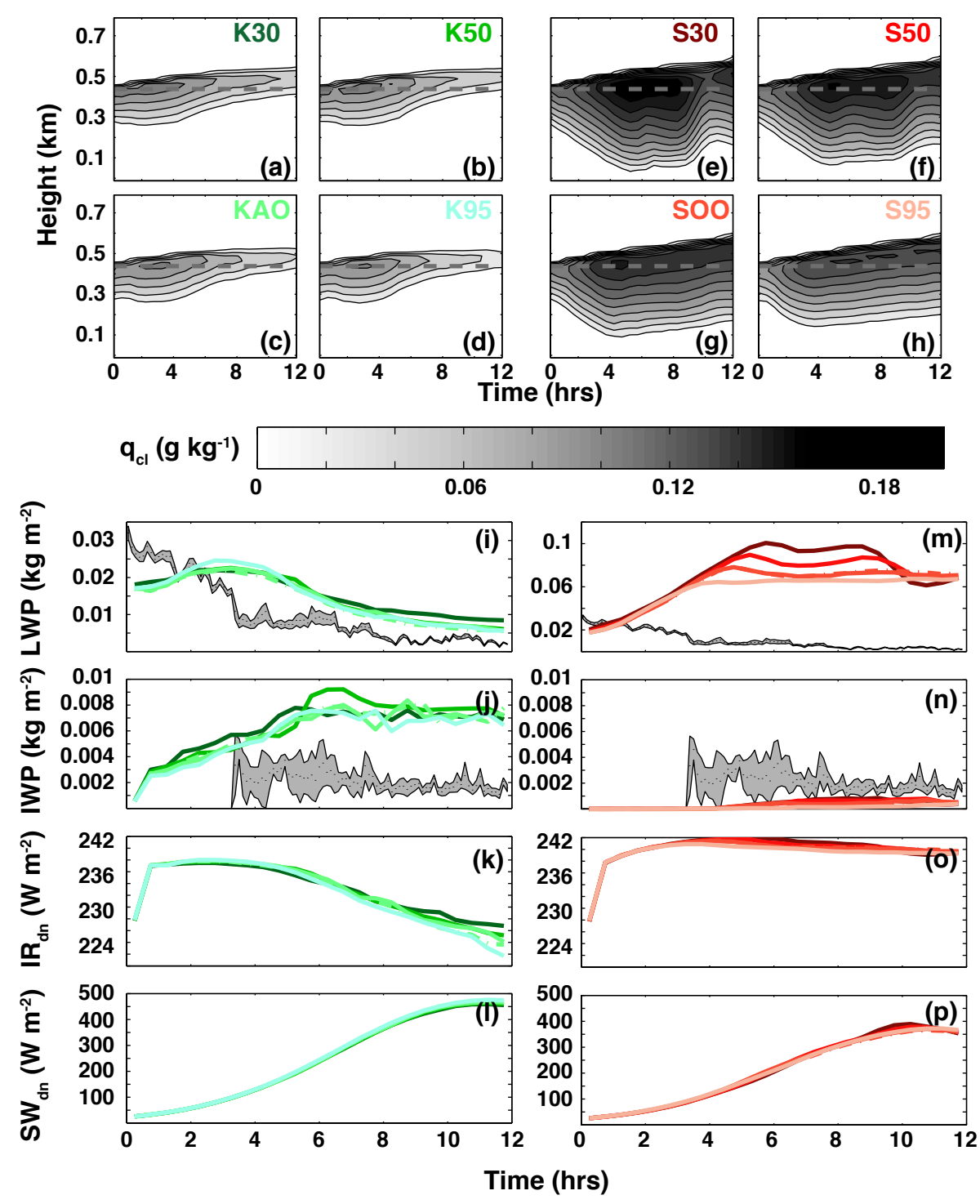

Fig. 8. Domain-averaged time-height cross sections of cloud water mixing ratio for Kaolinite (a-d) and Soot (e-f) simulations with different assumed soluble mass fractions. Included below are time series of domain-averaged mean liquid water path (i, m), ice water path $(\mathbf{j}, \mathbf{n})$, surface downwelling infrared radiation $(\mathbf{k}, \mathbf{o})$ and surface downwelling shortwave radiation (l, p) for the Kaolinite (left) and Soot (right) simulations with different soluble mass fraction assumptions. Observations are represented by the dotted line (mean) and grey shading (standard deviation).

mixed-phase clouds simulated by AMPS should be due to the impact of soluble mass fraction on the liquid droplet mass spectrum. Analysis similar to Fig. 5 for simulations featuring different amounts of aerosol soluble mass (not shown) reveals that there is only a small amount of variability in cloud-top temperature and droplet volume with time for these simulations, resulting in a relatively steady immersion freezing rate between the different simulations with time. While small, these differences are not negligible, as can be seen by the subtle differences in cloud liquid water mixing ratio plots (Fig. 8a-d and e-h). As demonstrated by the LWP timeseries, relative to simulated total LWP these differences are found to be larger for particles with lower freezing efficiencies. Simulations assuming a larger soluble mass fraction generally result in a thinner liquid cloud component. For Kaolinite, ice water paths and ice concentrations are comparable between simulations. However, the Soot simulations have larger differences, particularly in the number of ice crystals present within the mixed-phase layer. These differences are also brought out in the microphysical tendencies demonstrated in Fig. 9, where differences in freezing rates between SOO95 and SOO30 (Fig. 9d) simulations are roughly an order of magnitude. This also results in a large difference in the 


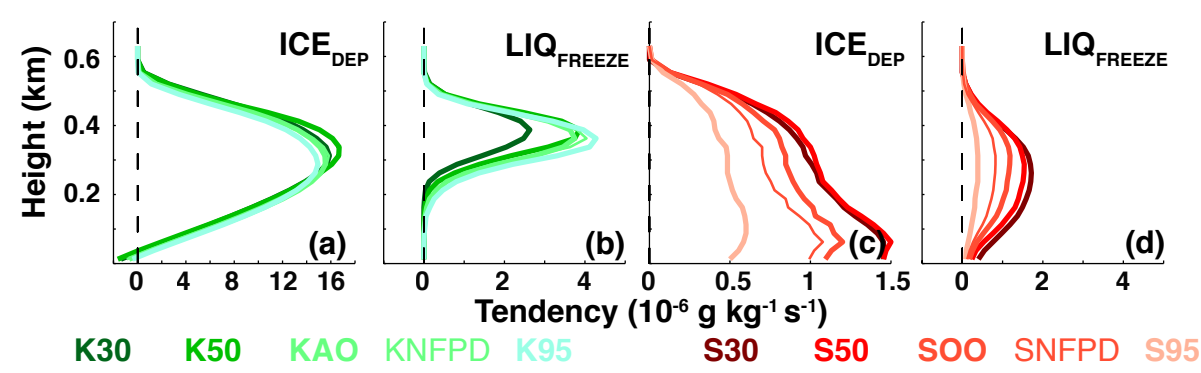

Fig. 9. Vertical profiles of domain-averaged microphysical tendencies for the second half of the $12 \mathrm{~h}$ simulation period from simulations featuring different soluble mass fractions (color coded at bottom). Simulations assume Kaolinite (a-d) or Soot (e-h) as the insoluble mass type Included are profiles of ice depositional growth tendency $(\mathbf{a}, \mathbf{c})$ and liquid freezing tendency (b, d).
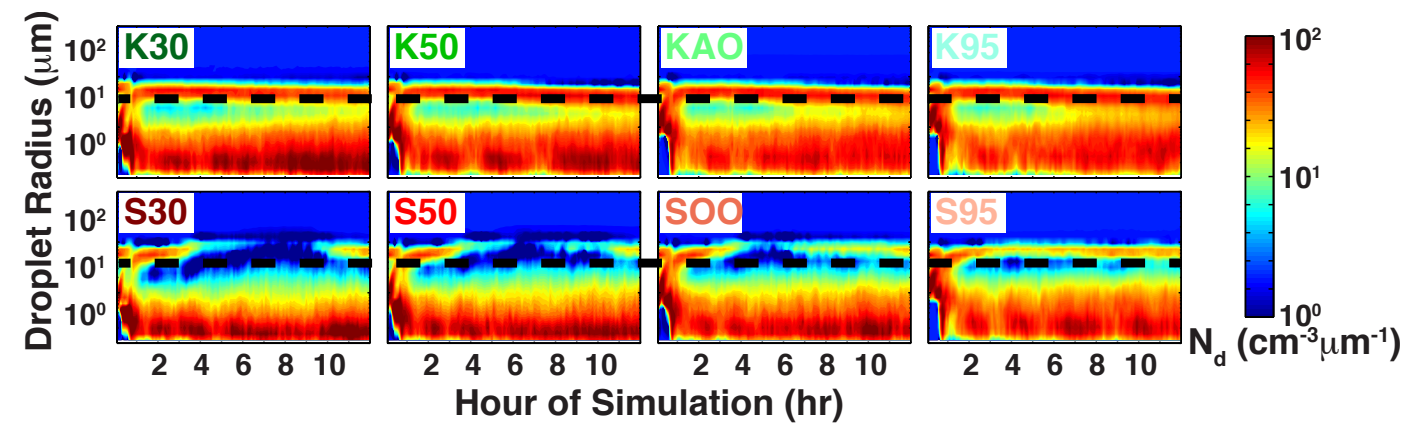

Fig. 10. Domain-averaged cloud-top size distributions for simulations featuring different aerosol soluble mass fractions at 5-min resolution. The top row includes simulations assuming Kaolinite as insoluble material, while the bottom row includes simulations assuming Soot. The dashed line indicates a radius of $10 \mu \mathrm{m}$.

amount of depositional growth (Fig. 9c) undergone by the ice mass.

The reasons behind the difference appears to lie in the impact of aerosol soluble mass content on $\mathrm{CN}$ activation. Although $\mathrm{CN}$ particle sizes are the same between simulations, the mass distributions are different. Because aerosol particles with larger soluble mass fractions have a higher critical radius for activation, a larger amount of water vapor is necessary to nucleate a liquid droplet. Additionally, the critical supersaturation for activation of liquid droplets decreases. When combined, these effects result in a broadening (larger mean droplet size while maintaining a large number of small droplets) of the liquid droplet size distribution in simulations with higher soluble mass fractions (Fig. 10). This increase in the concentration of large droplets causes slightly larger immersion freezing rates within the simulations with high soluble mass fraction (Fig. 11a, b and e-j). The oscillating patterns noticeable in the differences between SOO simulation freezing rates are the result of differences in the timing of ice formation in the simulations. The different aerosol soluble mass fractions also result in larger rain rates resulting from accelerated collision/coalescence processes in those simulations (Fig. 11, c, d and k-p) with higher soluble mass fractions. Combined, these effects result in a thinning of the liquid cloud component with increased aerosol soluble mass fraction. Comparison of the $\mathrm{SOO}$ and $\mathrm{KAO}$ rain mixing ratios demonstrates that aerosol impact on rain production is limited via ice nucleation in that aerosol particles with higher freezing efficiencies will freeze droplets prior to the size at which collision/coalescence takes over and initiates the rain process. This results in higher rain mixing ratios in the $\mathrm{SOO}$ simulations, and in larger differences between the SOO simulations than the KAO simulations.

\subsection{Variation of aerosol number density}

In order to evaluate the impact of $\mathrm{CN}$ concentration on the simulated cloud, three separate simulations were completed. These include KAO, the base Kaolinite case featuring $350 \mathrm{~cm}^{-3} \mathrm{CN}$, the mean measured $\mathrm{CN}$ concentration at SHEBA on 7 May, KLO, which was assigned the mean $\mathrm{CN}$ concentration of $72.2 \mathrm{~cm}^{-3}$ measured during the MixedPhase Arctic Clouds Experiment (MPACE, Verlinde et al., 2007), and KHI, for which the CN concentration is increased to $650 \mathrm{~cm}^{-3}$. In theory, higher aerosol concentrations should result in smaller droplet sizes, suppressing both liquid and ice precipitation due to decreased efficiency of both collision/coalescence and droplet freezing. Additionally, riming rates are impacted by droplet size, with larger droplets having a higher riming efficiency than smaller ones (Borys et al., 2000). Analysis of cloud top droplet volume and temperature reveals that the immersion freezing rate is governed primarily 

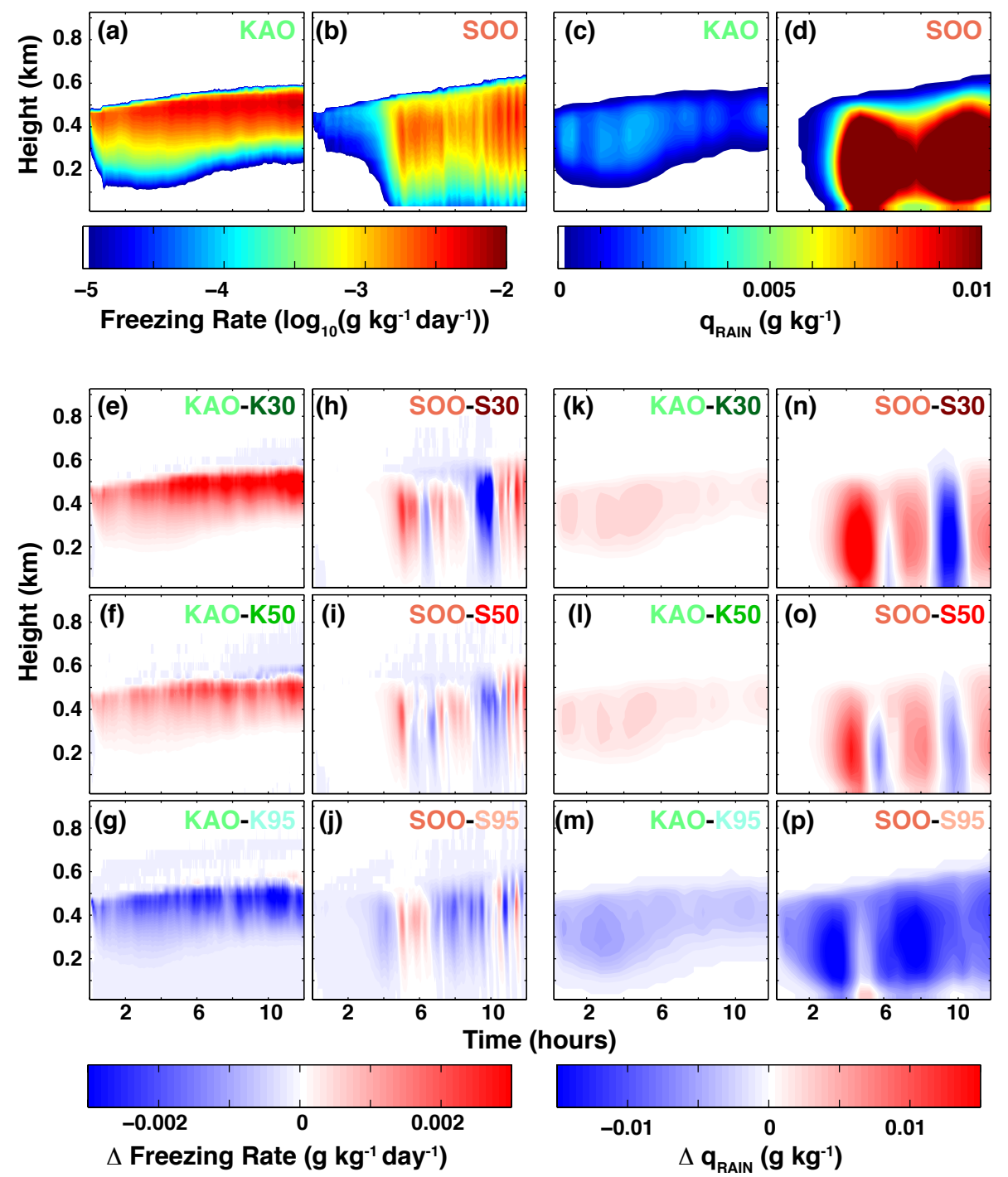

Fig. 11. Domain-averaged time-height cross-sections of immersion freezing rates for the KAO (a) and SOO (b) simulations, as well as differences between domain-averaged freezing rates in those simulations and simulations assuming different soluble mass fractions (e-j). Also plotted are domain-averaged time-height cross-sections of rain water mixing ratio for the KAO (c) and SOO (d) simulations, along with differences between domain-averaged rain water mixing ratios in those simulations and simulations assuming different soluble mass fractions (k-p).

through droplet volume when changing the aerosol concentration. There are some small differences in mean cloud top temperature, but these are generally less than $0.25 \mathrm{~K}$.

Figure 12 provides an overview of these simulations. The change in cloud water mixing ratio between the simulations is much smaller than that induced by changing the insoluble mass type. The simulation with the lowest number of $\mathrm{CN}$ maintains the largest LWP throughout much of the simulation period. Similarly, it features the most gradual increase in IWP of all of the simulations, despite having mean immersion freezing rates that are twice as high as those in the other simulations. Looking at mean ice crystal concentrations for the three simulations, KLO appears to have the most ice crys- tals for most of the 12-h simulations period (which is consistent with the higher nucleation rates). A combination of other factors appears to result in this simulation having higher liquid water paths and lower ice water paths than the others. First, an analysis of the crystal morphologies formed in these three simulations (not shown) provides some insight. KLO had more rimed crystals than either of the other simulations, while it had the least pristine crystals and aggregates. Second, an analysis of the liquid evaporation and coalescence rates indicates that cloud droplets in the KLO simulation coalesced more easily and evaporated less. The increased coalescence between cloud droplets results in the formation of a small number of larger drops which freeze preferentially 

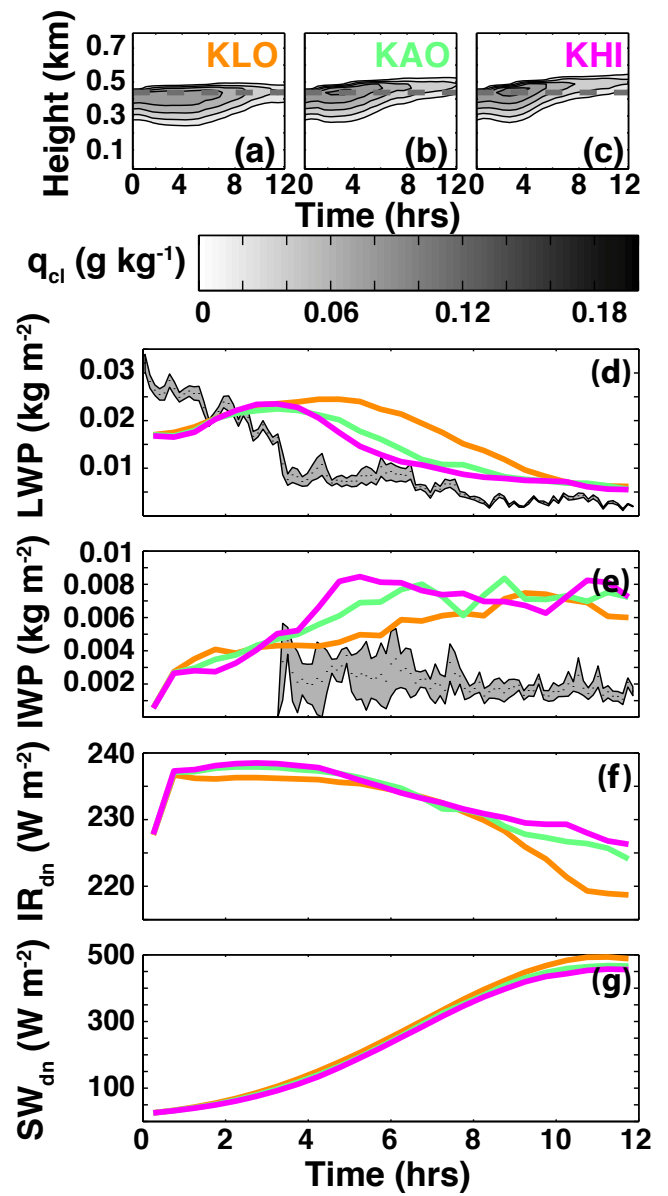

Fig. 12. An overview of simulation results assuming different aerosol concentrations. Included are domain-averaged time-height cross-sections of cloud water mixing ratio for the KLO (a), KAO (b) and KHI (c) simulations. Additionally included are time series for domain-averaged liquid water path (d), ice water path (e), surface downwelling longwave radiation (f), and surface downwelling shortwave radiation (g). Grey shading in the liquid and ice water path plots represent the mean \pm one standard deviation of observed values.

over smaller drops. This smaller number of larger ice crystals, when compared to simulations with higher $\mathrm{CN}$ concentrations, fall out of the cloud layer faster reducing the amount of water vapor removed through depositional growth of ice. The smaller concentration of ice crystals ultimately results in a reduced precipitation induced sink of total water from cloud level, leading to decreased small cloud droplet evaporation and increased LWP.

Microphysical tendencies for the simulations with different aerosol concentrations are shown in Fig. 13. All simulations have similar vertical structures, with some differences in magnitude. In particular, the KHI and KAO simulations feature lower droplet freezing rates (Fig. 13b) and increased liquid condensation rates (not shown) within the cloud layer as a result of the changes to the simulated liquid droplet size

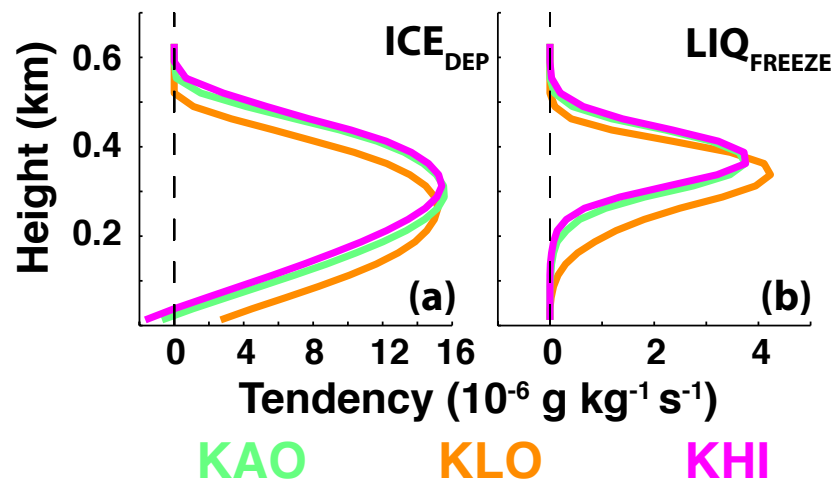

Fig. 13. Vertical profiles of domain-averaged microphysical tendencies for the second half of the $12 \mathrm{~h}$ simulation period from simulations featuring different aerosol concentrations (color coded at bottom). All simulations assume kaolinite as the insoluble mass type Included are profiles of ice depositional growth tendency (a) and liquid freezing tendency (b).

distributions (Fig. 14). There is also a vertical gradient on the efficiency of this relationship (Fig. 15, left), with areas in the very top of the cloud seeing less of an impact on the freezing rate due to the relatively large drops found there regardless of concentration. Once droplets are large enough to freeze efficiently, having a higher concentration of them results in the increase in ice mass tendency with concentration observed near the top of the cloud. An analysis of riming rates (Fig. 15, right) illustrates that initially the impact of $\mathrm{CN}$ concentration on riming is as expected, with higher $\mathrm{CN}$ concentrations resulting in lower amounts of riming (due to smaller droplet sizes). The transition in sign that occurs from the upper portion of the cloud to the lower portion demonstrates the relative impacts of droplet size and droplet concentration on riming rates. Simulations featuring higher aerosol concentrations tend to have smaller droplets, resulting in decreased riming lower in the cloud where the droplets are smaller. Near the top of the cloud, however, it appears as though the size effect on riming is overcome by the concentration effect, with a higher concentration of relatively large droplets (around $10 \mu \mathrm{m}$ ) resulting in higher riming amounts.

\section{Discussion and summary}

The presented model results demonstrate the ability of aerosol properties to modulate mixed-phase cloud lifetime and characteristics through the liquid phase. Several interaction pathways exist between aerosol and mixed-phase cloud properties. While the current study only provides a limited look into these pathways, it brings to light several competing factors in the relationships between aerosol properties and mixed-phase cloud lifetime. The complexity of the system is brought out in part by various local feedback mechanisms that influence how one aerosol property may impact the cloud 


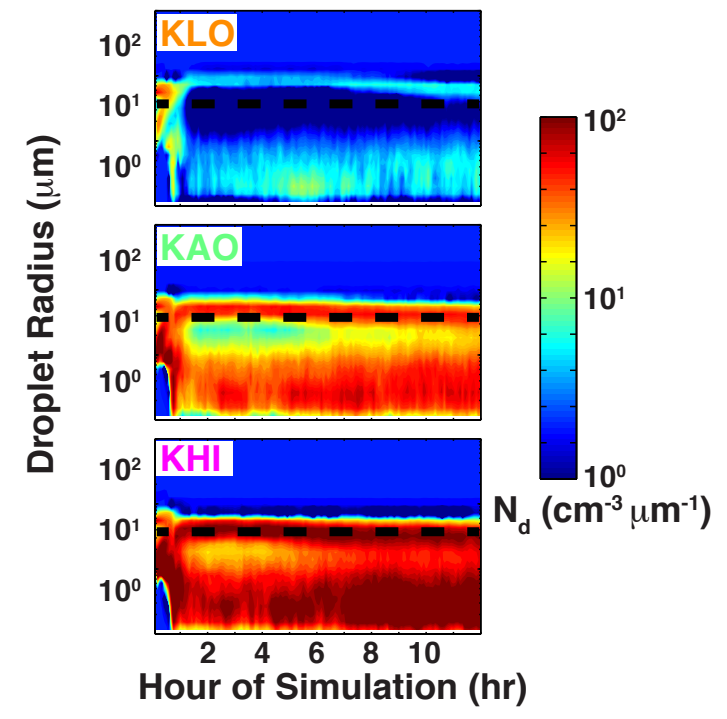

Fig. 14. Domain-averaged cloud-top size distributions for the KLO, $\mathrm{KAO}$ and $\mathrm{KHI}$ simulations at 5-min resolution. The dashed line indicates a radius of $10 \mu \mathrm{m}$.

structure via several pathways. An example of a positive local feedback involves the influence of aerosol soluble mass fraction on liquid condensational growth. This enhanced liquid condensational growth results in an increase in cloud liquid water, subsequently increasing cloud top radiative cooling rates. This increased cooling results in enhanced mixing via buoyant instability, increasing vertical motion. With this enhanced vertical motion comes increased supersaturation in the updrafts, further supporting additional condensational growth and production of cloud liquid water. Figure 8 demonstrates that this feedback does not dominate the production of liquid water however, since both the Kaolinite and Soot simulations have lower LWP with increased soluble mass fraction. This is because of the interplay between feedback mechanisms. In addition to positive feedback mechanisms as mentioned above, several negative local feedbacks are also initiated. One example includes the increase in ice depositional growth that occurs in conjunction with the elevated supersaturation occurring within stronger updrafts. This increased ice depositional growth will reduce local humidity and supersaturation, thereby reducing the amount of liquid growth in that portion of the cloud. These local feedbacks are only presented as examples, and many more interactions can be brought out of the internal connections between system components. While beyond the scope of the current work, a thorough analysis of these interactions and their magnitudes will likely result in invaluable insight into these complex cloud structures. The magnitudes of processes involved govern the system's ability to either achieve equilibrium or be pushed into an alternative (i.e. glaciated) state and may help to shed light on the resiliency issues discussed in more detail in Morrison et al. (2012).
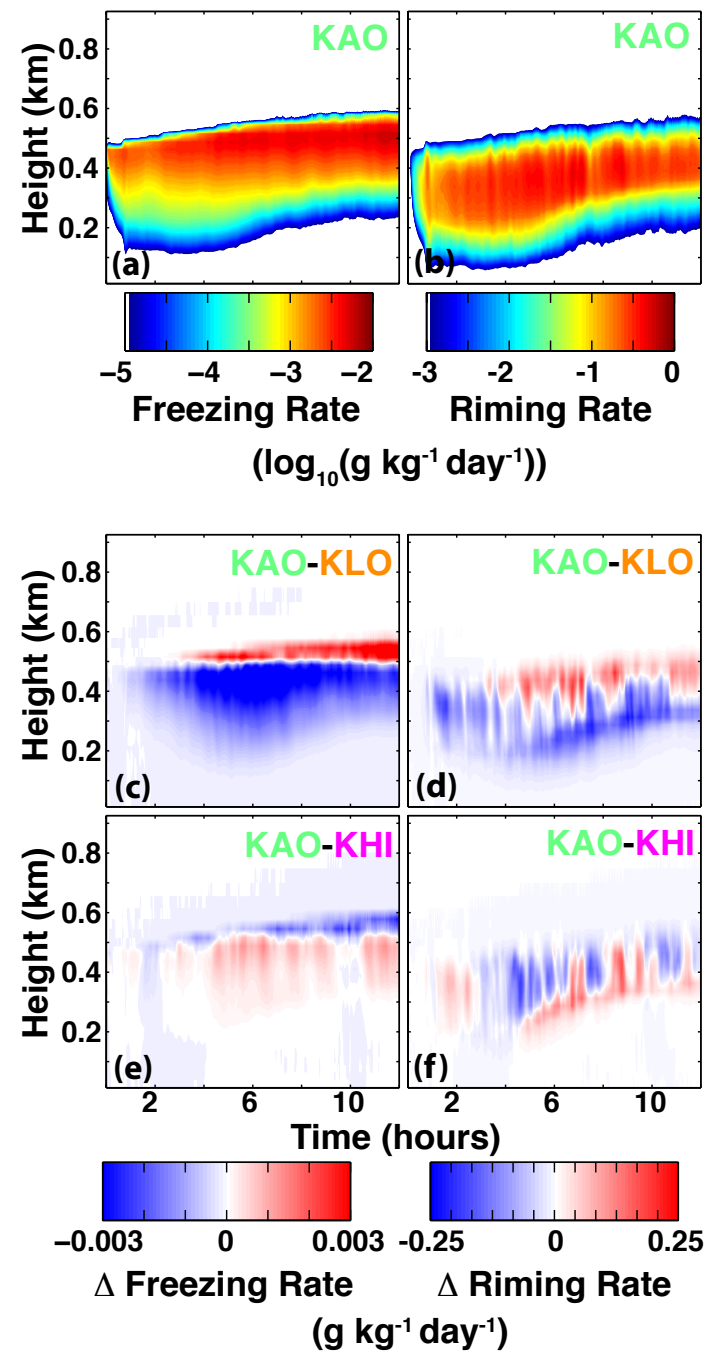

Fig. 15. An overview of droplet freezing and riming rates from simulations assuming different aerosol concentrations. Illustrated are domain averaged time-height cross-sections of freezing (a) and riming (b) rates for the simulations featuring SHEBA aerosol concentrations as well as the differences between these domain-averaged values for the KAO simulation and simulations featuring lower (c, d) and higher (e, f) aerosol amounts.

It is important to remember that this evaluation has been completed with a numerical model that is based on relationships observed in the laboratory. While these relationships appear to have a physical backing, there is certainly much work to be done to improve our understanding of cloud droplet microphysics and freezing. As discussed, the parameterizations used are based on limited measurements, and the use of alternative parameterizations may impact these results. Additionally, uncertainty in the estimation of the freezing efficiency constant used $\left(\mathrm{B}_{h, i}\right)$ is poorly constrained at this time. This means that the conclusions about the relative importance of aerosol properties on cloud microphysics and dynamics are only as good as the (poorly understood) 
uncertainties associated with the estimation of these parameters. Should, for example, the freezing efficiencies be uncertain within several orders of magnitude, freezing efficiency may become relatively less important for the net impact of aerosol on cloud lifetime and properties.

The use of a numerical model also results in the simplification of some aspects of the natural system, including the use of $\mathrm{CN}$ with identical composition in each simulation. This is unrealistic for the true atmosphere, as the atmospheric aerosol population is likely a mix of many different particle types and soluble mass fractions. Future work on the aerosol component of this model should involve the separation of properties between different modes of the aerosol spectrum in order to, for example, allow for only the largest aerosol particles to include insoluble components. Additionally, the current model configuration does not take into account the freezing of subcritical haze droplets. This has potentially large impacts on the number of liquid cloud droplets and ice crystals formed under the various scenarios tested.

Given these caveats, we can draw some conclusions on the impacts of aerosol properties on the microphysics and dynamics of stratiform mixed-phase clouds from the current set of numerical simulations. In general, insoluble aerosol type freezing efficiency was illustrated to have a larger influence on the overall cloud lifetime than the soluble mass fraction of the aerosol particle or the aerosol concentration. This appears to be consistent with work by Murray et al. (2011) and Hoffer (1961) who demonstrate large differences in measured droplet freezing due to the particle types studied. Using laboratory-derived values for freezing efficiencies, the spectrum of values used was demonstrated to result in a range of cloud scenarios, including a completely glaciated sky for particles with high freezing efficiencies, and thick, robust clouds for particles with low freezing efficiencies. While none of the simulations matched observed cloud liquid and ice properties for this particular SHEBA-based case, this is not necessarily surprising. One reason this is not surprising is that we initialize the cloud simulations using observed conditions (including water amount), but do not allow the cloud simulation to "spin up" and produce cloud-driven dynamics to support liquid before introducing ice. Therefore, we would not necessarily expect that the equilibrium state would match the observations. Having said this, the intent of this work was not necessarily to reproduce the SHEBA case, but rather to explore the influence of changes to the parameter space of aerosol properties and their influences on liquid-related processes. To this extent, observational estimates were included in some of the analysis to provide an example of realistic ratios of ice to liquid under the large-scale conditions used to force the simulations.

Freezing point depression introduced through the soluble material associated with aerosol particles appears to have very limited impacts on the freezing of droplets once those droplets have reached sizes typical of those found in stratiform clouds (approximately $10 \mu \mathrm{m}$ ). Where aerosol parti- cle soluble mass does appear to impact a cloud is through increased growth of liquid droplets. This results in a modified drop size distribution, impacting ice-relevant properties such as droplet freezing rate and riming. The connection between larger droplets and increased ice nucleation is one that has been observed in several observational campaigns (e.g. Lance et al., 2011; Rangno and Hobbs, 2001). This connection, while not completely understood, remains an interesting pathway between aerosol properties such as soluble mass fraction and number concentration and the production of ice crystals.

In summary, several pathways linking aerosol concentration and composition and mixed-phase cloud properties are presented. These pathways range from the impact of droplet size on in-cloud riming rate, to the influence of aerosol insoluble mass type on ice nucleation through droplet freezing, to impacts of aerosol properties on rain production within these clouds. The resulting changes to cloud properties result in large changes in surface and atmospheric energy budgets through the influence on surface radiation. With only small changes to these energy budgets necessary for large impacts on things like sea ice concentration and extent (Kwok and Untersteiner, 2011), these aerosol-cloud interactions have a potentially large impact on Arctic climate. While a significant amount of work to fully understand these interactions remains, the current results shed light on several interesting and important mechanisms for these interactions.

Acknowledgements. The authors wish to acknowledge Dr. Karoline Diehl for her suggestions and assistance during the completion of this work and Hugh Morrison and Paquita Zuidema for their work in compiling the intercomparison document on which this work is based. Additionally, we'd like to thanks Drs. Matthew Shupe and David Turner for providing data for simulation validation. This research was supported in part by the Director, Office of Science, Office of Biological and Environmental Research of the US Department of Energy under Contract No. DE-AC02-05CH11231 as part of their Climate and Earth System Modeling Program, completed at the Lawrence Berkeley National Laboratory, managed by the University of California under the same grant. Finally, we would like to acknowledge additional funding from the National Aeronautics and Space Administration (NASA: NNX07AQ81G) and from the United States Department of Energy (US DOE: DE-SC0008794). G. B. was additionally supported by NSF grants ARC-1023366 and ARC-1203902. This work was prepared in part at the Cooperative Institute for Research in Environmental Sciences (CIRES) with support in part from the National Oceanic and Atmospheric Administration, US Department of Commerce, under cooperative agreement NA17RJ1229 and other grants. The statements, findings, conclusions, and recommendations are those of the author and do not necessarily reflect the views of the National Oceanic and Atmospheric Administration or the Department of Commerce. 
Edited by: G. Feingold

\section{References}

Albrecht, B.: Aerosols, cloud microphysics, and fractional cloudiness, Science, 245, 1227-1230, 1989.

Avramov, A. and Harrington, J.: Influence of parameterized ice habit on simulated mixed phase Arctic clouds, J. Geophys. Res., 115, D03205, doi:10.1029/2009JD012108, 2010.

Bergeron, T.: On the Physics of clouds and precipitation, in: Proces Verbaux de l'Association de Meteorologie, 156-178, International Union of Geodesy and Geophysics, 1935.

Bigg, E.: The formation of atmospheric ice crystals by the freezing of droplets, Q. J. Roy. Meteor. Soc., 79, 510-519, 1953.

Bigg, E. and Leck, C.: Cloud Active Particles over the Central Arctic Ocean, J. Geophys. Res., 106, 32155-32166, 2001.

Borys, R., Lowenthal, D., and Mitchell, D.: The relationships among cloud microphysics, chemistry, and precipitation rate in cold mountain clouds, Atmos. Environ., 34, 2593-2602, 2000.

Bretherton, C., Macvean, M., Bechtold, P., Chlond, A., Cotton, W., Cuxart, J., Cuijpers, H., Khairoutdinov, M., Kosovic, B., Lewellen, D., Moeng, C.-H., Siebesma, A., Stevens, B., Stevens, D., Sykes, I., and Wyant, M.: An intercomparison of radiaitvely driven entrainment and turbulence in a smoke cloud, as simulated by different numerical models, Q. J. Roy. Meteor. Soc., 125, 391423, 1999.

Broadley, S., Murray, B., Herbert, R., Atkinson, J., Dobbie, S., Malkin, T., Condliffe, E., and Neve, L.: Immersion mode heterogeneous ice nucleation by an illite rich powder representative of atmospheric mineral dust, Atmos. Chem. Phys., 12, 287-307, doi:10.5194/acp-12-287-2012, 2012.

Clough, S., Shephard, M., Mlawer, E., Delamere, J., Iacono, M., Cady-Pereira, K., Boukabara, S., and Brown, P.: Atmospheric radiative transfer modeling: a summary of the AER codes, J. Quant. Spectrosc. Radiat. Transf., 91, 233-244, 2005.

de Boer, G., Eloranta, E., and Shupe, M.: Arctic Mixed-Phase Stratiform Cloud Properties from Multiple Years of Surface-Based Measurements at Two High-Latitude Locations, J. Atmos. Sci., 66, 2874-2887, doi:10.1175/2009JAS3029.1, 2009.

de Boer, G., Hashino, T., and Tripoli, G. J.: A Theory for Ice Nucleation Through Immersion Freezing in Mixed-Phase Stratiform Clouds, Atmos. Res., 96, 315-324, doi:10.1016/j.atmosres.2009.09.012, 2010.

de Boer, G., Morrison, H., Shupe, M., and Hildner, R.: Evidence of liquid dependent ice nucleation in high-latitude stratiform clouds from surface remote sensors, Geophys. Res. Lett., 38, L01803, doi:10.1029/2010GL046016, 2011.

Diehl, K. and Wurzler, S.: Heterogeneous Drop Freezing in the Immersion Mode: Model Calculations Considering Soluble and Insoluble Particles in the Drops, J. Atmos. Sci., 61, 2063-2072, 2004.

Diehl, K., Simmel, M., and Wurzler, S.: Numerical sensitivity studies on the impact of aerosol properties and drop freezing modes on the glaciation, microphysics, and dynamics of clouds, J. Geophys. Res., 111, D07202, doi:10.1029/2005JD005884, 2006.

Findeisen, W.: Kolloid-Meteorologische, American Meteorological Society, 2nd edn., 1938.

Fukuta, N.: Experimental investigations on the ice-forming ability of various chemical substances, J. Meteor., 15, 17-26, 1958.
Harrington, J. and Olsson, P.: On the potential influence of ice nuclei on surface-forced marine stratocumulus dynamics, J. Geophys. Res., 106, 27473-27484, 2001.

Hashino, T. and Tripoli, G.: The spectral Ice Habit Prediction System (SHIPS). Part I: Model description and simulation of the vapor deposition process, J. Atmos. Sci., 64, 2210-2237, 2007.

Hoffer, T.: A laboratory investigation of droplet freezing, J. Meteor., 18, 766-778, 1961.

IPCC: Climate Change 2007: The Physical Science Basis, Tech. rep., 2007.

Jiang, H., Cotton, W., Pinto, J., Curry, J., and Weissbluth, M.: Cloud resolving simulations of mixed-phase Arctic stratus observed during BASE: Sensitivity to concentration of ice crystals and large-scale heat and moisture advection, J. Atmos. Sci., 57, 2105-2117, 2000.

Jiang, H., Xue, H., Teller, A., Feingold, G., and Levin, Z.: Aerosol Effects on the Lifetime of Shallow Cumulus, Geophys. Res. Lett., 33, L14806, doi:10.1029/2006GL026024, 2006.

Kay, J., LEcuyer, T., Gettelman, A., G., S., and O'Dell, C.: The contribution of cloud and radiation anomalies to the 2007 Arctic sea ice extent minimum, Geophys. Res. Lett., 35, L08503, doi:10.1029/2005JD005884, 2008.

Khvorostyanov, V. and Curry, J.: The theory of ice nucleation by heterogeneous freezing of deliquescent mixed CCN. Part I: Critical radius, energy, and nucleation rate, J. Atmos. Sci., 61, 26762691, 2004.

Khvorostyanov, V. and Curry, J.: The theory of ice nucleation by heterogeneous freezing of deliquescent mixed CCN. Part II: Parcel model simulation, J. Atmos. Sci., 62, 261-285, 2005.

Koehler, K., Kreidenweis, S., De Mott, P., Petters, M., Prenni, A., and Carrico, C.: Hygroscopicity and cloud droplet activation of mineral dust particles, Geophys. Res. Lett., 36, L08805, doi:10.1029/2009GL037348, 2009.

Kwok, R. and Untersteiner, N.: New high-resolution images of summer sea ice, EOS, 92, 53-54, 2011.

Lance, S., Shupe, M. D., Feingold, G., Brock, C. A., Cozic, J., Holloway, J. S., Moore, R. H., Nenes, A., Schwarz, J. P., Spackman, J. R., Froyd, K. D., Murphy, D. M., Brioude, J., Cooper, O. R., Stohl, A., and Burkhart, J. F.: Cloud condensation nuclei as a modulator of ice processes in Arctic mixed-phase clouds, Atmos. Chem. Phys., 11, 8003-8015, doi:10.5194/acp-11-80032011, 2011.

Levine, J.: Statistical explanation of spontaneous freezing of water droplets, Tech. Rep. 2234, NACA, 1950.

Lohmann, U. and Diehl, K.: Sensitivity Studies of the Importance of Dust Ice Nuclei for the Indirect Aerosol Effect on Stratiform Mixed-Phase Clouds, J. Atmos. Sci., 63, 968-982, 2006.

Lu, M.-L. and Seinfeld, J.: Study of the Aerosol Indirect Effect by Large-Eddy Simulation of Marine Stratocumulus, J. Atmos. Sci., 62, 3909-3932, 2005.

Menon, S., Del Genio, A., Kaufman, Y., Bennartz, R., Koch, D., Loeb, N., and Orlikowski, D.: Analyzing Signatures of AerosolCloud Interactions from Satellite Retrievals and the GISS GCM to Constrain the Aerosol Indirect Effect, J. Geophys. Res., 113, D14S22, doi:10.1029/2005JD005884, 2008.

Morrison, H. and Zuidema, P.: GCSS/WMO Cloud Modeling Workshop Arctic Mixed-Phase Stratus Model Intercomparison, 2008. 
Morrison, H., Zuidema, P., Ackerman, A., Avramov, A., de Boer, G., Fan, J., Fridlind, A., Hashino, T., Harrington, J., Luo, Y., Ovchinikov, M., and Shipway, B.: Intercomparison of cloud model simulations of Arctic mixed-phase boundary layer clouds observed during SHEBA, J. Adv. Model. Earth. Syst., 3, M06003, doi:10.1029/2011MS000066, 2011.

Morrison, H., de Boer, G., Feingold, G., Harrington, J., Shupe, M., and Sulia, K.: Self-Organisation and Resillience of persistent Arctic mixed-phase clouds, Nature Geosci., 5, 11-17, 2012.

Murray, B. J., Broadley, S. L., Wilson, T. W., Atkinson, J. D., and Wills, R. H.: Heterogeneous freezing of water droplets containing kaolinite particles, Atmos. Chem. Phys., 11, 4191-4207, doi:10.5194/acp-11-4191-2011, 2011.

Prenni, A., De Mott, P., Rogers, D., Kreidenweis, S., McFarquhar, G., Zhang, G., and Poellot, M.: Ice nuclei characteristics from MPACE and their relation to ice formation in clouds, Tellus, 61B, 436-448, 2009.

Pruppacher, H. and Klett, J.: Microphysics of Clouds and Precipitation, Kluwer Academic Publishers, Boston, 2 edn., 1997.

Rangno, A. and Hobbs, P.: Ice Particles in Stratiform Clouds in the Arctic and Possible Mechanisms for the Production of High Ice Concentrations, J. Geophys. Res., 106, 15065-15075, 2001.

Roberts, P. and Hallett, J.: A laboratory study of the ice nucleating properties of some mineral particulates, Q. J. Roy. Meteor. Soc., 94, 204-205, 1968.

Shupe, M., Matrosov, S., and Uttal, T.: Arctic Mixed-Phase Cloud Properties Derived from Surface-Based Sensors at SHEBA, J. Atmos. Sci., 63, 697-711, 2006.

Tripoli, G. J.: A nonhydrostatic mesoscale model designed to simulate scale interaction, Mon. Weather Rev., 120, 1342-1359, 1992.
Twomey, S.: The Influence of Pollution on the Shortwave Albedo of Clouds, J. Atmos. Sci., 34, 1149-1152, 1977.

Uttal, T., Curry, J., McPhee, M., Perovich, D., Moritz, R., Maslanik, J., Guest, P., Stern, H., Moore, J., Turenne, R., Heiberg, A., Serreze, M., Wylie, D., and Persson, P.: Surface Heat Budget of the Arctic Ocean, B. Am. Meteor. Soc., 83, 255-275, 2002.

Verlinde, J., Harrington, J., McFarquhar, G., Yannuzzi, V., Avramov, A., Greenberg, S., Johnson, N., Zhang, G., Poellot, M., Mather, J., Turner, D., Eloranta, E., Zak, B., Prenni, A., Daniel, J., Kok, G., Tobin, D., Holz, R., Sassen, K., Spangenberg, D., Minnis, P., Tooman, T., Ivey, M., Richardson, S., Bahrmann, C., Shupe, M., De Mott, P., Heymsfield, A., and Schofield, R.: The Mixed-Phase Arctic Cloud Experiment, B. Am. Meteor. Soc., 88, 205-221, 2007.

Walko, R., Cotton, W., Feingold, G., and Stevens, B.: Efficient computation of vapor and heat diffusion between hydrometeors in a numerical model, Atmos. Res., 53, 171-183, 2000.

Wegener, A.: Thermodynamik der Atmosphäre, Leipzig, Germany, 1911.

Yum, S. and Hudson, J.: Vertical distribution of cloud condensation nuclei spectra over the springtime Arctic Ocean, J. Geophys. Res., 106, 15045-15052, 2001.

Zhou, J., Swietlicki, E., Berg, O., Aalto, P., Hämeri, K., Nilsson, E., and Leck, C.: Hygroscopic Properties of Aerosol Particles over the Central Arctic Ocean During Summer, J. Geophys. Res., 106, 32111-32123, 2001.

Zimmerman, F., Weinbruch, S., Schütz, L., Hofmann, H., Ebert, M., Kandler, K., and Worringen, A.: Ice nucleation properties of the most abundant mineral dust phases, J. Geophys. Res., 113, D23204, doi:10.1029/2008JD010655, 2008. 